\title{
AN ANALYSIS OF SOUND FOR FAULT ENGINE
}

\author{
${ }^{1,2}$ Suphattharachai Chomphan and ${ }^{1}$ Theerathan Kingrattanaset \\ ${ }^{1}$ Department of Electrical Engineering, Faculty of Engineering at Si Racha, \\ Kasetsart University, 199 M.6, Tungsukhla, Si Racha, Chonburi, 20230, Thailand \\ ${ }^{2}$ Center for Advanced Studies in Industrial Technology, Kasetsart University, \\ 50 Ngam Wong Wan Rd, Ladyaow, Chatuchak, Bangkok, 10900, Thailand
}

Received 2013-09-25; Received 2013-12-04; Accepted 2014-04-15

\begin{abstract}
Various types of faults of the gasoline engine may result in similar symptoms. Sound analysis of engine has been conducted to diagnose the engine faults. This study presents a study of sound analysis of the normal engine and the engine with three different fault conditions. The gasoline engine was our target of this study. The engine sound has been recorded by using a microphone at the engine room for three directions. Three conditions of engine faults including the engine that is not smooth while idling, the engine that goes missing while idling and the engine that has no power are simulated. In the signal processing of the sound, we use five signal features including fundamental frequency, long term spectrum, energy, long term cestrum and zero crossing rate. Thereafter, the important differences between normal engine and the fault engines are concluded. These proposed signal features can be used to discriminate all three conditions and the engine with normal condition effectively.
\end{abstract}

Keywords: Sound Analysis, Gasoline Engine, Fundamental Frequency, Long Term Spectrum, Signal Energy, Long Term Cestrum, Zero Crossing Rate, Accelerometer

\section{INTRODUCTION}

Signal processing in mechanical systems is a challenging tool in modern interdisciplinary study of electrical and mechanical areas. Signal analysis can be applied for diagnosing faults of the engine, since several techniques of signal processing have been rapidly enhanced. A number of appropriated techniques of signal processing are developed for vibration analysis. This study aims at developing a tool for assisting the engine mechanic to diagnose the engine faults.

A number of techniques of sound intensity have been used to analysis of engine front noise by (Hong and Bing, 2005). In the study, sources of environmental noise were investigated and the noise level was deteriorated by using signal processing techniques for the diesel engines subsequently.

Sharkey et al. (2000) used cylinder pressure and vibration signal to verify the robust faults in the engine fault diagnosis. Modgil et al. (2004) conducted the diagnostics of vibration for the engine test cells. Moreover, the vibration signal had been preliminarily employed especially for the marine engine by (Zhan et al., 2007). Meanwhile, Klinchaeam and Nivesrangsan (2010) applied the vibration signal to monitor the valve clearance faults on a small four strokes petrol engine. It has been concluded from several studies that the vibration signal plays a very significant role in the engine diagnosis with signal processing applications.

To analyze the engine vibration, the accelerometer has been widely used at the surface of the engine case to measure the vibration in the form of acceleration for all directions. A number of important features are extracted from the measured acceleration signals, for examples, mean of periodic peaks, mean of periodic off-peaks (Wongchai et al., 2012; Tiun et al., 2012), fundamental frequency, energy, cepstrum coefficients and zero crossing rate. These features are expected to distinguish all cases of the engine faults. At the beginning period, the gasoline engines for personal cars have been selected in this study since they have been widely used in the all cities of the world.

It can be obviously seen from the previous studies that both sound and vibration signals play significant Corresponding Author: Suphattharachai Chomphan, Department of Electrical Engineering, Faculty of Engineering at Si Racha, Kasetsart University, 199 M.6, Tungsukhla, Si Racha, Chonburi, 20230, Thailand 
roles in the mechanical systems with signal processing. Therefore, this study applies the sound signal compared with the vibration signal in the previous work for the gasoline engine diagnostics.

\section{MATERIALS AND METHODS}

\subsection{Experimental Design}

The experimental design is presented in Fig. 1. It is a diagram for sound signals of the engine. It can be seen that the signals are collected into an engine database and a fault engine database as depicted in the top of the figure. The calculation of signal parameters is performed for both of the engine database and the fault engine database. The signal parameters from both databases are subsequently compared. After that the empirical differences between normal engine and the fault engines are investigated from the corresponding figures. All in all the data analysis is performed to show the differences between the normal engines the simulated fault engines.

Three following important conditions of engine faults are selected from a number of conditions of engine faults which are normally found in the engine mechanic workshop. The gasoline engine with 4 cylinders of 1497-cc displacement is chosen as a test bed, because of the silent sound, the well-known brand and the economical spare parts:

- $\quad$ Engine is not smooth while idling (ripple)

- Engine goes missing while idling (jerk)

- Engine has no power (powerless)

\subsection{Parameter Calculation}

In this study, five parameters of signal features are calculated based on the methods proposed by Hong and Bing (2005) as shown below.

Long term Spectrum: The well-known transformation technique of Fast Fourier Transform (FFT) analysis was performed. As for sound signal database, the sampling rate of $16,000 \mathrm{~Hz}$ is set as default.

Long term cepstrum: Cepstral analysis is a nonlinear signal processing technique which is widely applied in speech signal processing and homomorphic filtering. The cepstral analysis procedure is presented in Fig. 2 (Chomphan, 2012; Shanmugam et al., 2011).

Fundamental Frequency (F0): The essential lowest frequency of signal is extracted. This frequency is a principal value existing in the signal of frequency domain. The F0 extraction is applied to the sound signals directly.

Energy: A signal is often treated as a function of varying amplitude through time domain, it has been proved that the measurement of the strength of a signal would be the area under the curve in case of analog signal. To avoid the area residing in the a negative part, the energy a signal is defined as the area under the squared signal. In case of discrete signal, the definition of signal energy is defined as the sum of the squared magnitude of the samples.

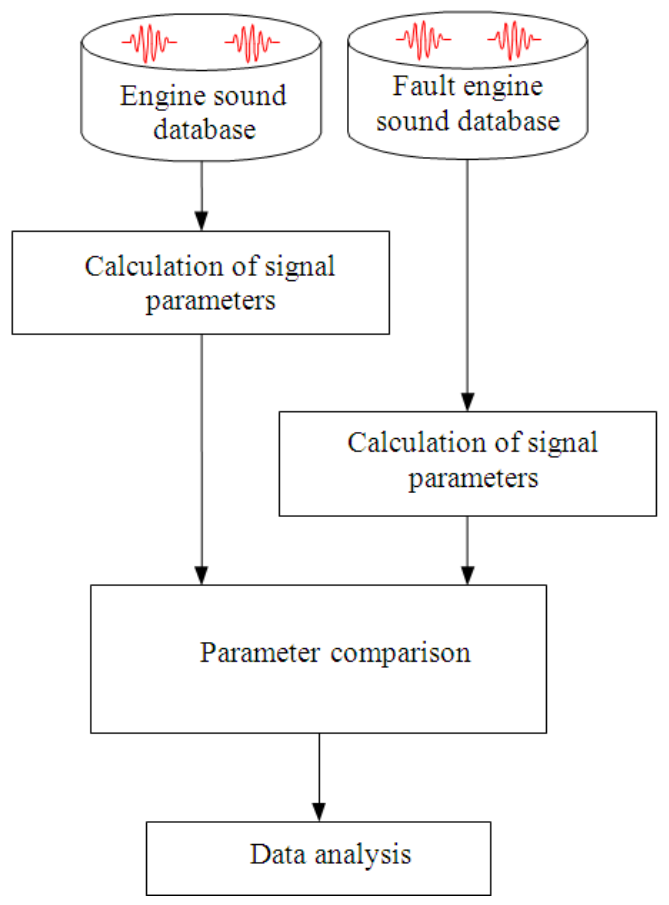

Fig. 1. Block diagram of the experimental design for sound signals

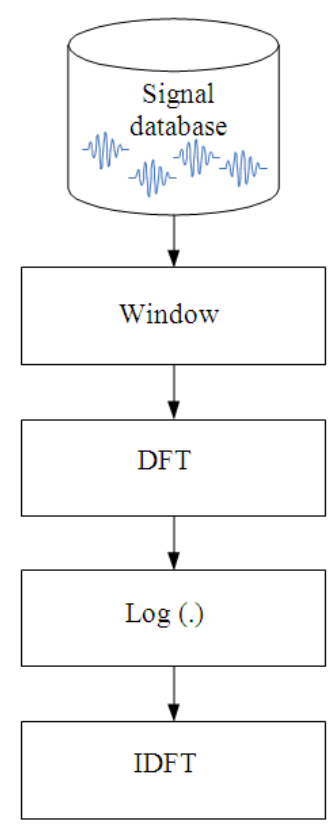

Fig. 2. Cepstral analysis procedure of the signal database 
Zero Crossing Rate: In case of discrete signal, a zero crossing is defined when the successive samples of the sequence have different algebraic signs. The rate at which zero crossings occur is a simple measure of the frequency content of a sequence.

\subsection{Parameter Comparison}

The sound signal database is separated into two cases of normal engine and fault engine. In case of fault engine databases, there are three subsets for three important conditions of engine faults including the engine that is not smooth while idling (ripple), the engine that goes
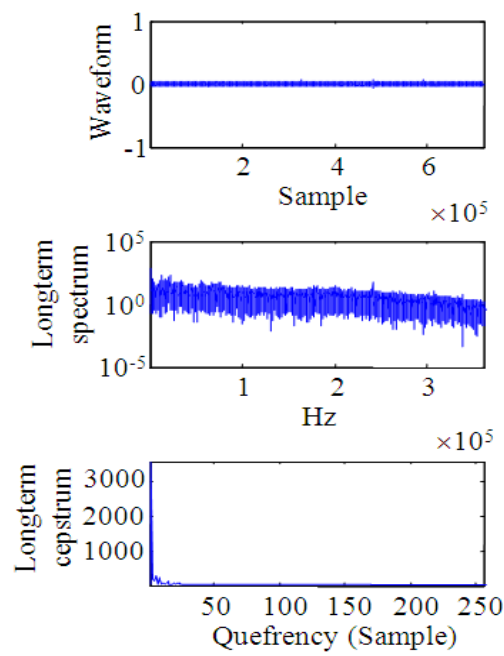

missing while idling (jerk) and the engine that has no power (powerless). Each subset performs the same way as that of the normal engine database. The parameter of signal features for each case of fault engine was compared with that of the normal case.

\section{RESULTS}

The total signal is computed by taking sum square of all signals in three directions. They are shown in the following figures comparatively. The four figures (Fig. 3-6) are of sound signals.
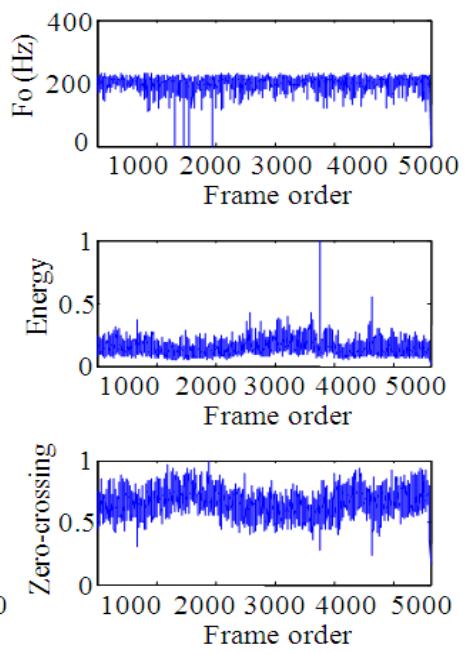

Fig. 3. Five parameters extracted from the sound of engine with normal condition
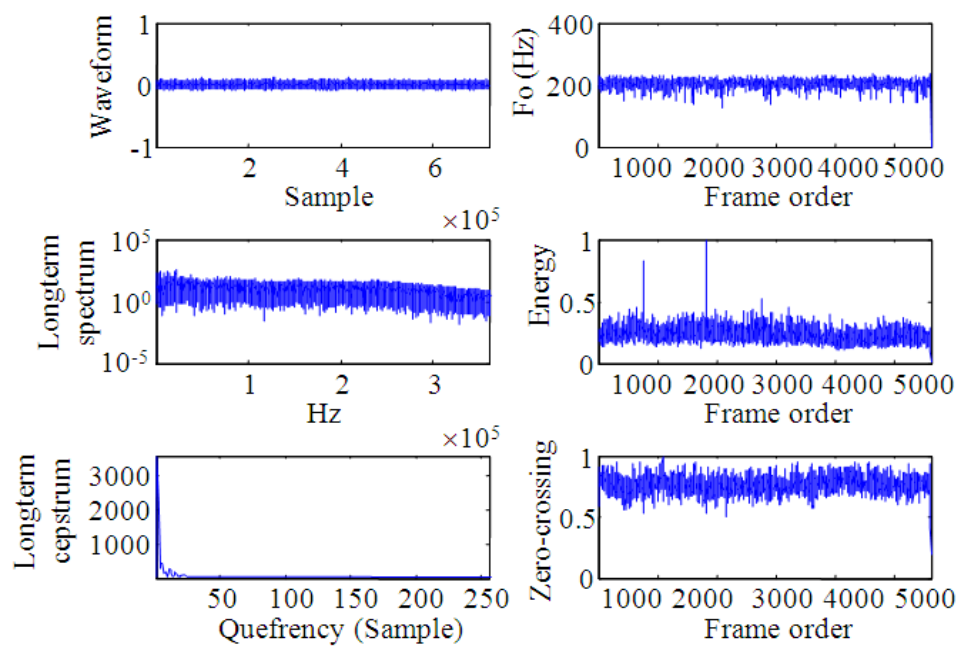

Fig. 4. Five parameters extracted from the sound of engine that is not smooth while idling (ripple) 

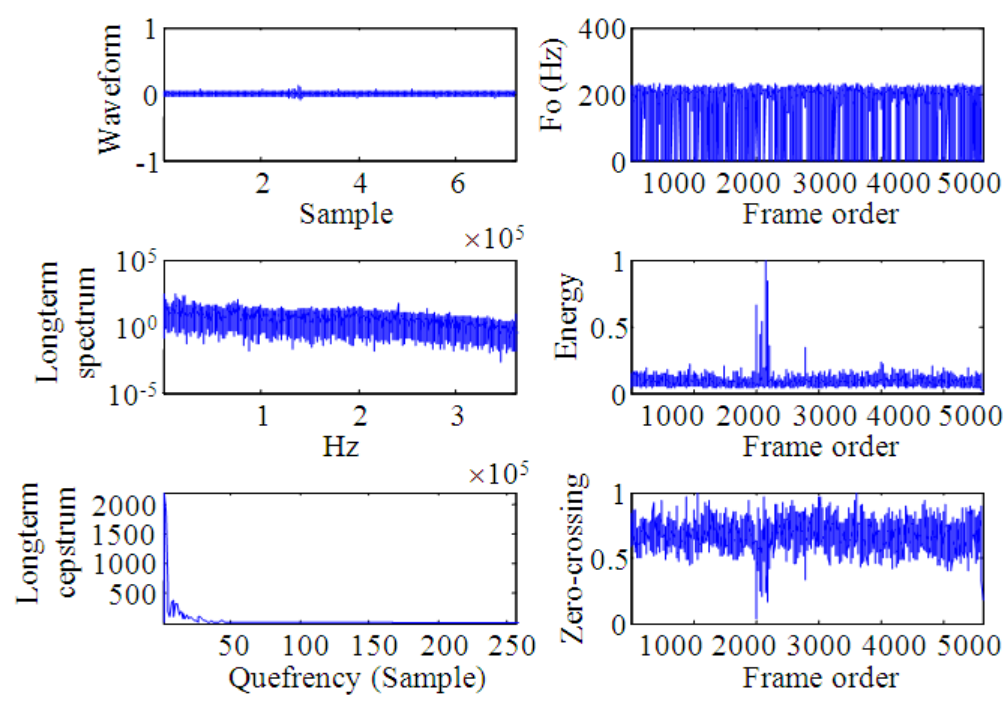

Fig. 5. Five parameters extracted from the sound of engine that goes missing while idling (jerk)
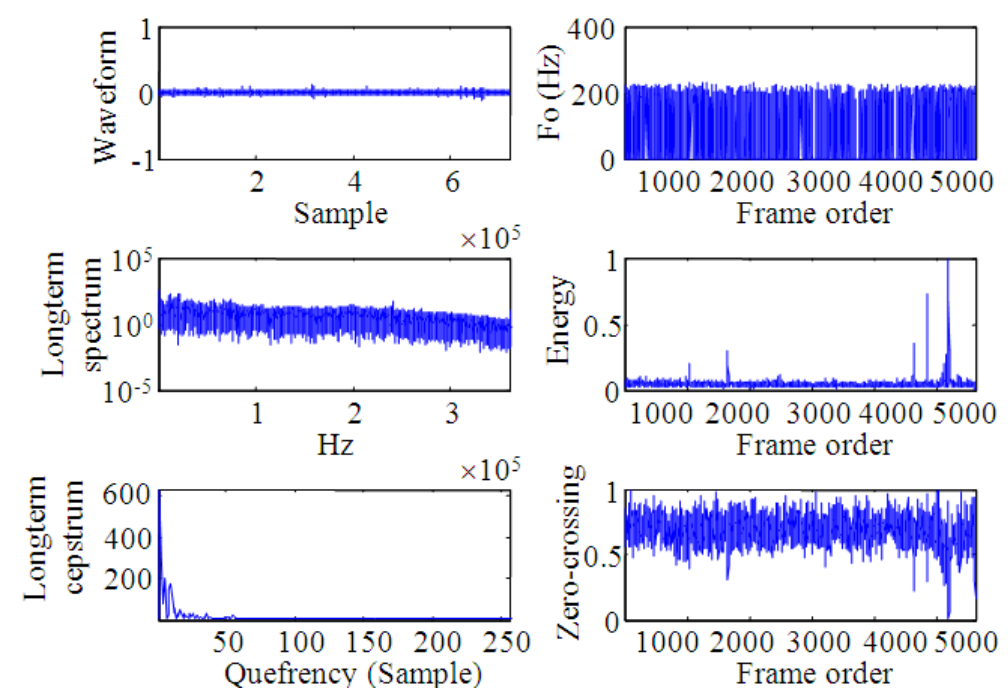

Fig. 6. Five parameters extracted from the sound of engine that has no power (powerless)

\section{DISCUSSION}

Considering the parameters of the sound of the engine in Fig. 3-6, it can be seen that the spectrum, cepstrum and zero crossing rate are not different for all cases of engine faults and normal case. On the other hands, F0 are almost all at the level of $200 \mathrm{~Hz}$. In case of normal engine and the engine that is not smooth while idling (ripple), the variance are however quite lower than that of other cases. Meanwhile, the averaged energy levels for all cases are different. The energy level of the engine that has no power (powerless) is lowest, while the energy level of the engine that is not smooth while idling (ripple) is highest.

\section{CONCLUSION}

The study of sound analysis of engine with three different fault conditions including the engine that is not smooth while idling (ripple), the engine that goes missing while idling (jerk) and the engine that has no power 
(powerless) are presented. Five parameters of signal features of sound signals from both normal engine and fault engine databases are calculated and subsequently compared. The significant differences between normal engine and the fault engines are presented from the corresponding figures. The signal parameters of F0, long term spectrum, energy, long term cestrum and zero crossing rate are explicitly able to discriminate all three fault engines and the normal engine.

\section{ACKNOWLEDGEMENT}

The researcher is grateful to Kasetsart University, for the research grants through Kasetsart University Research and Development Institute and for the supports through the center for advanced studies in industrial technology.

\section{REFERENCES}

Chomphan, S., 2012. Effects of noises on fundamental frequency extraction using cepstral analysis for thai dialects. Am. J. Applied Sci., 9: 1415-1421. DOI: 10.3844/ajassp.2012.1415.1421

Hong, Z.J. and H. Bing, 2005. Analysis of engine front noise using sound intensity techniques. J. Mechanical Syst. Signal Process., 19: 213-221. DOI: 10.1016/j.ymssp.2004.03.007

Klinchaeam, S. and P. Nivesrangsan, 2010. Condition monitoring of valve clearance fault on a small four strokes petrol engine using vibration signals. Songklanakarin J. Sci. Technol., 32: 619-625.
Modgil, G., R.F. Orsagh and M.J. Roemer, 2004. Advanced vibration diagnostics for engine test cells. Proceedings of the IEEE Conference of Aerospace, Mar. 6-13, IEEE Xplore Press. DOI: 10.1109/AERO.2004.1368143

Shanmugam, N., A.B. Suryanarayana, S. TSB, D. Chandrashekar and C.N. Manjunath, 2011. A novel approach to medical image segmentation. J. Comput. Sci., 7: 657-663. DOI: 10.3844/jcssp.2011.657.663

Sharkey, A.J.C., G.O. Chandroth and N.E. Sharkey, 2000. Acoustic emission; cylinder pressure and vibration: A multisensor approach to robust fault diagnosis. Proceedings of the IEEE-INNS-ENNS International Joint Conference on Neural Networks, (NN '00), IEEE Xplore Press, Como, pp: 223-228. DOI: $10.1109 / \mathrm{IJCNN} .2000 .859400$

Tiun, S., R. Abdullah and T.E. Kong, 2012. Restricted domain malay speech synthesizer using syntaxprosody representation. J. Comput. Sci., 8: 19611969. DOI: $10.3844 /$ jcssp.2012.1961.1969

Wongchai, B., P. Visuwan and S. Chuepeng, 2012. Cylinder pressure variations of the fumigated hydrogen-diesel dual fuel combustion. Am. J. Applied Sci., 9: 1967-1973. DOI: 10.3844/ajassp.2012.1967.1973

Zhan, Y.L., Z.B. Shi, T. Shwe and X.Z. Wang, 2007. Fault diagnosis of marine main engine cylinder cover based on vibration signal. Proceedings of the International Conference on Machine Learning and Cybernetics, Aug. 19-22, IEEE Xplore Press, Hong Kong, $\quad$ pp: 1126-1130. DOI: 10.1109/ICMLC.2007.4370313 